\title{
A Comparative Study of Blended Learning Activities between Two Classes
}

\author{
Eugenia M. W. Ng \\ The Hong Kong Institute of Education, Hong Kong, China \\ eugenia@ied.edu.hk
}

\begin{abstract}
Numerous studies on blended learning suggested that students embraced this learning approach and yet there are not much comparative studies on the merits of online versus face-to-face activities. Online discussion, online debate and face-to-face debates between two classes of undergraduate student teachers were conducted. The author was interested to examine if the blended approach with another class would enhance learning. Data are analyzed from tracked statistics provided by the learning platform and the subjects' opinions on a questionnaire. It was found the numbers of views for online postings were enormous but the number of messages posted was not that many. Students gave the highest ratings to the question on "having face-to-face activities with students of the other class has added value to my learning" and the lowest ratings to the question on "I feel more comfortable to communicate with my teachers and classmates online rather face-to-face". The findings suggest that student teachers have no problem of using information technology to support different activities but they still preferred the traditional face-to-face learning activities.
\end{abstract}

Keywords: blended-learning, online learning, on-line debate, student teachers

\section{Introduction}

Blended learning is a teaching approach that incorporates technologies with regular face-to-face teaching depending on the module requirements and the needs of the learners (Alonso, López, Manrique, \& Vines, 2005; Osguthorpe \& Graham, 2003). Blended learning offers the convenience of the online environments without losing face-to-face meetings (Dziuban, Hartman, \& Moskal, 2004). The word "blend" means allowing greater flexibility, responsibility and control to students for their learning activities (Garrison \& Kanuka, 2004). However, blended learning may also refer to a combination of different modalities or delivery media (Harden \& Hart, 2002). For example, educators can ask students to tackle online quizzes so that they can have a better understanding of the students' prior knowledge of the topic and to enhance their zones of proximal development. Educators can also lecture on key concepts during class hours and ask students to participate in

Material published as part of this publication, either on-line or in print, is copyrighted by the Informing Science Institute. Permission to make digital or paper copy of part or all of these works for personal or classroom use is granted without fee provided that the copies are not made or distributed for profit or commercial advantage AND that copies 1) bear this notice in full and 2) give the full citation on the first page. It is permissible to abstract these works so long as credit is given. To copy in all other cases or to republish or to post on a server or to redistribute to lists requires specific permission and payment of

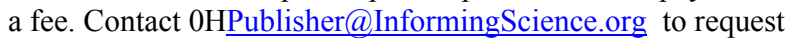
redistribution permission. online discussions on controversial issues after classes.

Indeed, the success of using blended learning approach is not only confined to using more than one delivery mode but to incorporate collaborative learning among participants. In the main, the learners and academics interact, share ideas and support one another throughout the learning process (Boyle, 2005). Re- 
searchers have found that students can discuss varied issues in greater depth and their critical thinking skills are considerably enhanced in the process (Tan, Turgeon, \& Johansson, 2001); learners are better able to assimilate new information and solve problems when working in collaboration with others (Ocker \& Yaverbaum, 2002); and learners' levels of involvement and incentives to learn have also increased significantly with a wider and more complete understanding of the subject knowledge (Eleuterio \& Bortolozzi, 2004).

Blended learning provides educators with an additional platform to apply new teaching strategies and it is imperative that our future teachers develop such abilities and skills for independent and life-long learning. The teachers then can cultivate these same abilities and skills for their pupils at schools. In fact, a number of studies had indicated that teacher education did not adequately prepare teachers to teach with technology (Pope, Hare, \& Howard, 2002; Selinger, 2001) and in order to successfully implement this, it was suggested that teacher education systems should integrate content, pedagogy and technology (Hughes, 2005; Koehler, Mishra, \& Yahya, 2007). Furthermore, most of the research providing evidence on the merits of blended learning concentrated on the merits of e-learning rather than comparing face-to-face versus online activities. "Evaluating the quality of blended learning experiences is no easy matter, as technologies typically support only part of the learning processes that the students engage in" (Ginns \& Ellis, 2007, p. 54). Therefore, in this study the author conducted some online and face-to-face activities between two classes of undergraduate student teachers to examine if blended learning can enhance learning.

\section{Literature Review}

Many researchers have conducted research studies on blended learning but the findings are mixed. Various blended learning activities with university students will be elaborated below to delineate the contradictory claims. Fang (2007) conducted face-to-face sessions every week which was followed by a three-hour project presentation session at the end of the semester for university students. The online sessions were conducted concurrently with the face-to-face sessions using an online learning platform. The participants were required to learn online, and they had to respond to "the content, the trainer, the senior Student Ambassadors (who acted as online coaches or chat leaders), and each other" (Fang, 2007, p. 244). The participants found this blended learning experience beneficial because they had the flexibility to learn at their own pace, reflect and recapitulate what was taught in class. They enjoyed this new learning experience and found it less stressful, as it allowed them to complete their work at any time. Furthermore, they felt connected socially with other participants and learnt useful computer skills which could benefit their future studies (Fang, 2007).

A blended learning program, SCHOLAR, was designed to "support pupils in the post-compulsory years of schooling in Scotland studying for national examinations (Higher and Advanced Higher) in the key areas of science, mathematics and computing studies (Condie \& Livingston, 2007) in Scotland. It consists of text booklets complemented by online resources which are the electronic versions of the texts with additional animations and simulations, short assessment exercises, revision materials, a notice board and a discussion forum. Although this program was strongly promoted by the local authorities, there was lots of resistance from teachers. They felt that the online learning programs and independent study did not cater for learners' diverse learning abilities. Some of them suggested that students needed to be self-motivated and mature enough to learn in this mode. They also stated that teaching using a blended mode required new pedagogic skills. Indeed, the evaluation of SCHOLAR revealed that some teachers were reluctant to adopt the new technology because they were uncomfortable in trying out new approaches which might have a negative impact on examination results (Condie \& Livingston, 2007). 
Zuckerman-Parker et al. (2010) describe a research based educational intervention designed to support participants in the United States with "lifelines" using blended learning so they could further their education and enter the biotechnology workforce. This holistic educational approach focuses on individualized learning using technology to foster personal skill development and mentoring from industry professionals. Quantitative data and qualitative data showed that those participants who had been using the technology to learn and to reflect performed better than those who did not use the technology. Technology also provided a safe haven for participants to express themselves, a medium to reduce and mediate stress.

Guy and Wishart (2010) adopted different teaching approaches for students who took online courses in the United States who were mainly blacks. They changed the teaching strategy for the e-learning class from student-centered to instructor-centered to even more instructor-centered for the three years. Students' grades of face-to-face and online courses were compared but it was found that neither the strategy nor the delivery method had any impact on student performances. The interesting results are rather different from other research findings. In light of contradictory findings on blended learning, this article will compare some online activities and face-to-face activities between two classes and to examine if blended learning could add value to their learning.

\section{The Study}

\section{Participants}

The participants were 14 undergraduate final year students (thereafter, MAIE students) who took a four-year joint-program by the Hong Kong University of Science and Technology (HKUST) and a one-year professional teacher education provided by the Hong Kong Institute of Education (HKIEd) and 14 undergraduate second year students (thereafter, BEd students) studying Bachelor of Education at HKIEd. The MAIE students were studying both mathematics and information technology at HKUST while completing education and teaching methods modules at HKIEd. The MAIE participants took "Supporting Information Technology in Schools" whilst BEd students attended a module called Information Technology Supported Learning Environment (ITSLE) during the same semester with the author. The medium of instructions for the MAIE class was Chinese whilst the BEd class was in English. Since both languages are official languages of the Hong Kong Special Administrative Region, all university students are competent in both languages.

\section{Activities}

Teaching requires good communication skills and subject knowledge and it is completely inappropriate to replace regular lectures wholly with online studies. On the other hand, there is a need to integrate technology in teaching and learning, in order to enable student teachers to learn through experiential learning. Face-to-face interaction included standard face-to-face lectures and other classroom activities, whereas online activities included facilitating online discussion and online debate so that student teachers could experience the advantages and disadvantages of using a blended learning approach. Student-centered online activities were organized as Bruner (1986) believed that learning was an active social process in which learners construct new ideas of concepts based on current knowledge. Furthermore, "as far as possible, teachers could promote students' reasoning and critical thinking rather than fostering the belief that teachers are authorities of knowledge and students should merely memorize the knowledge transmitted in class" (Chan, 2003, p.47). 


\section{Online discussion}

Since BEd class had higher class participation assessment weighting, they were asked to facilitate online discussion on various topics as an ongoing activity. Figure 1 showed that groups of students had to assume the role as expert in their chosen topic. Both MAIE and BEd classes were asked to answer the questions posted by the facilitators who had to facilitate the follow-up discussion online by giving feedback to their peers.

\begin{tabular}{|c|c|c|c|c|}
\hline $\begin{array}{l}\text { Display } \\
\text { Order }\end{array}$ & Forum & Total Posts & $\begin{array}{l}\text { Unread } \\
\text { Posts }\end{array}$ & \begin{tabular}{|c|} 
Total \\
Participants
\end{tabular} \\
\hline $1 \vee$ & $\frac{\text { Week } 3 \text { - } 22 \text { January } 2008}{\text { Facilitators: Chan Hoi Man, Chiu Fung Yee }}$ & 22 & 0 & 19 \\
\hline $2 \vee$ & $\frac{\text { Week } 4 \text { - } 29 \text { January } 2008}{\text { Facilitators: Wong Yuen Man, Leung Wing Yan, Lai Bun Lee, Wong Chin Hung }}$ & 14 & 0 & 12 \\
\hline $3 \vee$ & $\frac{\text { Week } 5 \text { - } 12 \text { Feb } 2008}{\text { Facilitators: Chu Yim Yee, Chan Chui Ki, Wong Jack Chi Ho }}$ & 16 & 0 & 16 \\
\hline $4 \vee$ & $\frac{\text { Week } 6 \text { - } 19 \text { Feb } 2008}{\text { Facilitators: Wong Sze Man, Mok Chue Fan, Law Ching Yin }}$ & 17 & 0 & 16 \\
\hline $5 \vee$ & Week 7 - 26 Feb 2008 & 20 & 0 & 19 \\
\hline & Facilitators: Hui Pui Sin, Mak Kai Yu, Lee Chun Ming & & & \\
\hline h $\mathrm{h}$ & Debate I- 28 Feb $(12: 30-1: 00)$ & 6 & 0 & 5 \\
\hline
\end{tabular}

Figure 1: Screen shot of the Discussion Forum.

For example, a group of BEd students led the discussion about using technology to teach the topic of puberty as shown in Figure 2. This group of students gave the background information of their chosen topic including the contents of puberty for primary five and six students. They provided some relevant web sites and asked other students to visit those websites and find out their key features. The questions included: (1) which websites are more suitable for Primary five and six students? (2) what are the differences between them? and (3) which are their target audiences.

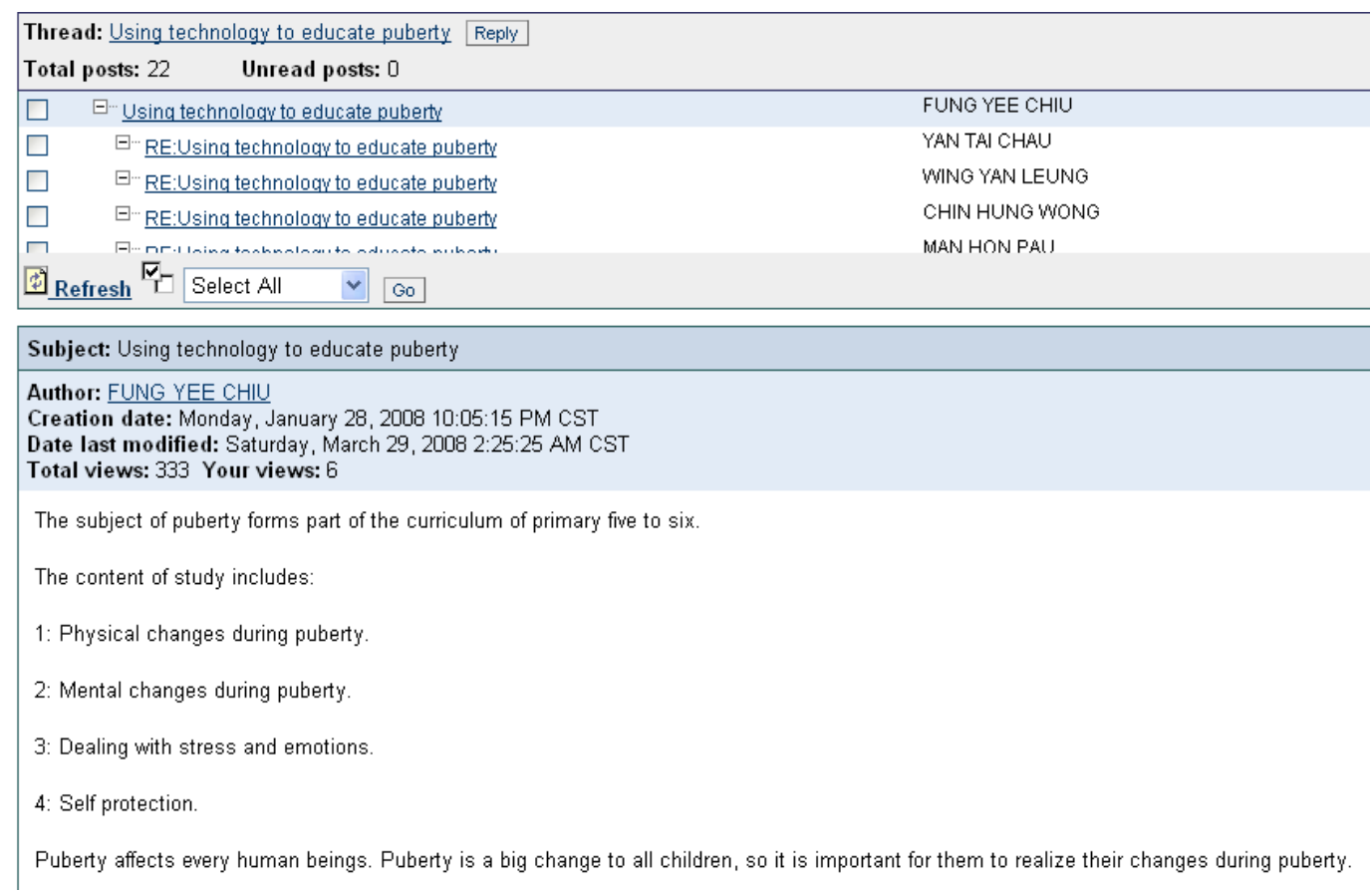

Figure 2: Screen shot of a post from students.

\section{Debates}

There were three debates between the two classes; one was an online debate whilst the other two debates were face-to-face. Since both classes had the same number of students, they were randomly assigned to each group as long as each group consisted of students from the two classes. Each team 
came up with different topics of interests to debate. The first debate topic was "will using information technology reduce the importance of teachers", the second debate was "the more we use information technology, the more distance we feel" and the last topic was "using information technology to teach is more effective than not using it". They drew lots to decide if they would join the "for" or "against" group. For the face-to-face debate, two classes sat together in the same classroom. As for the online debate, each team was stationed in one classroom which was just next door. They had to decide on the sequence of the speaking and how to proceed in the debate. Each class watched the other debate team members on the screen in the classrooms. Other classmates were also encouraged to put down their opinions in the pertinent discussion forums.

\section{Findings and Discussion}

\section{Tracking Functions}

Five discussion forums were created between week 3 to week 7 of the module delivery for two classes to discuss. Figure 3 showed that the number of views varied from over 434 to over 860 even though the number of views tended to decrease with time. However, we are mindful that number of views do not guarantee an in-depth reading by the participants. Furthermore, some of the views have been inflated due to the author's checking on them whilst composing this article. Nevertheless, the average view's figure had still been very impressive. Table 1 showed that the number of postings were relatively few as there had been less than one message per student for each discussion topic. As for the debate, hardly any classmates put down their opinions in the pertinent discussion forums. Perhaps they were too attentive to the debate discussion.



Week 3 - Week 4 - Week 5 - Week 6 - Week 7 -

22 January 29 January 12 Feb 19 Feb 26 Feb $\begin{array}{lllll}2008 & 2008 & 2008 & 2008 & 2008\end{array}$

Figure 3: Number of views

Table 1: No of postings per weekly activity

\begin{tabular}{|l|l|l|l|l|l|l|}
\hline & Week 3 & Week 4 & Week 5 & Week 6 & Week 7 & Total/class \\
\hline BEd & 20 & 10 & 10 & 14 & 12 & 69 \\
\hline MAIE & 7 & 5 & 5 & 3 & 6 & 30 \\
\hline Total/week & 27 & 15 & 15 & 17 & 18 & 99 \\
\hline
\end{tabular}




\section{Findings from Questionnaire}

Participants were asked to fill in a questionnaire related to different learning activities towards the end of the semester. The measurement instrument was developed using a five-point Likert-type scale where "1" stands for "Strongly Disagree", "2" stands for "Disagree", "3" stands for "Neutral, "4" stands for "Agree" and "5" stands for "Strongly Agree". There were 28 valid returns and the results were shown in Table 2. They gave the highest ratings to Q1-Having face-to-face activities with students of the other class has added value to my learning and the lowest ratings to Q3 - I feel more comfortable to communicate with my teachers and classmates online rather face-to-face. This finding reinforced the fact that students prefer face-to-face activities to online actvities.

It was very clear that the BEd students gave much higher ratings to all questions asked (see Table 2). Two classes had the largest difference of opinions on Q4 - Blended learning enables me to learn more effectively than using only face-to-face approach. (see Figure 4). The least difference between two classes of respondents was Q1-Having face-to-face activities with students of the other class has added value to my learning. The responses centered at disagree to agree, but BEd students tended to agree, and MAIE students tended to disagree (see Figure 5). However, the largest standard devision was Q3 - I feel more comfortable to communicate with my teachers and classmates online rather face-to-face which suggested that students of the same classes had very different opinions. The findings suggested that both groups of students had different preferences on blended learning approach and they preferred face-to-face meetings rather than online activities in general.

Table 2: Mean and standard deviation of questionnaire items

\begin{tabular}{|l|l|l|l|l|l|l|}
\hline & \multicolumn{2}{|c|}{ MAIE } & \multicolumn{2}{c|}{ BEd } & \multicolumn{2}{c|}{ Total } \\
\hline & Mean & S.D & Mean & S.D. & Mean & S.D. \\
\hline $\begin{array}{l}\text { Q1. Having face-to-face activities with students } \\
\text { of the other class has added value to my learn- } \\
\text { ing. }\end{array}$ & 0.5 & 4 & 0.39 & 3.75 & 0.7 \\
\hline $\begin{array}{l}\text { Q2. Having online activities with students of the } \\
\text { other class has added value to my learning. }\end{array}$ & 2.71 & 0.99 & 3.5 & 0.85 & 3.11 & 0.99 \\
\hline $\begin{array}{l}\text { Q3. I feel more comfortable to communicate } \\
\text { with my teachers and classmates online rather } \\
\text { face-to-face. }\end{array}$ & 2.5 & 1.02 & 3.29 & 1.07 & 2.89 & 1.1 \\
\hline $\begin{array}{l}\text { Q4. Blended learning enables me to learn more } \\
\text { effectively than using only face-to-face ap- } \\
\text { proach. }\end{array}$ & 2.57 & 0.65 & 3.54 & 0.66 & 3.04 & 0.81 \\
\hline $\begin{array}{l}\text { Q5. Blended learning increases the opportunity } \\
\text { for me to gain more perspectives than only } \\
\text { face-to-face approach. }\end{array}$ & 2.86 & 0.86 & 3.43 & 0.65 & 3.14 & 0.8 \\
\hline
\end{tabular}




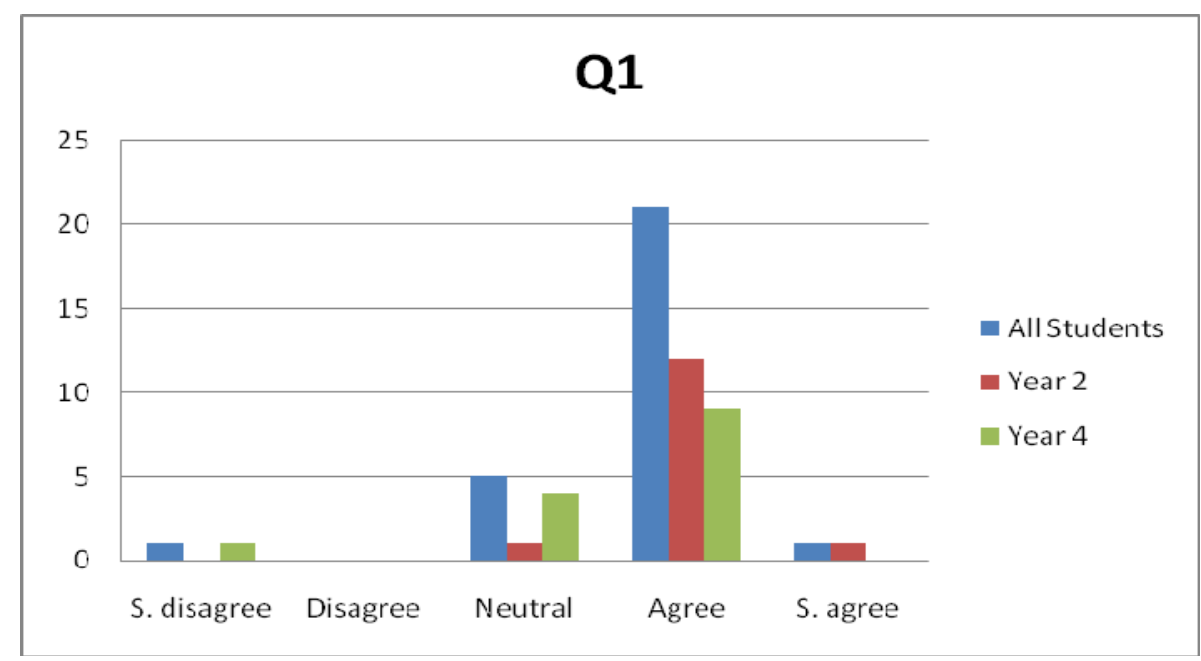

Figure 4: Having face-to-face activities with students of the other class has added value to my learning.

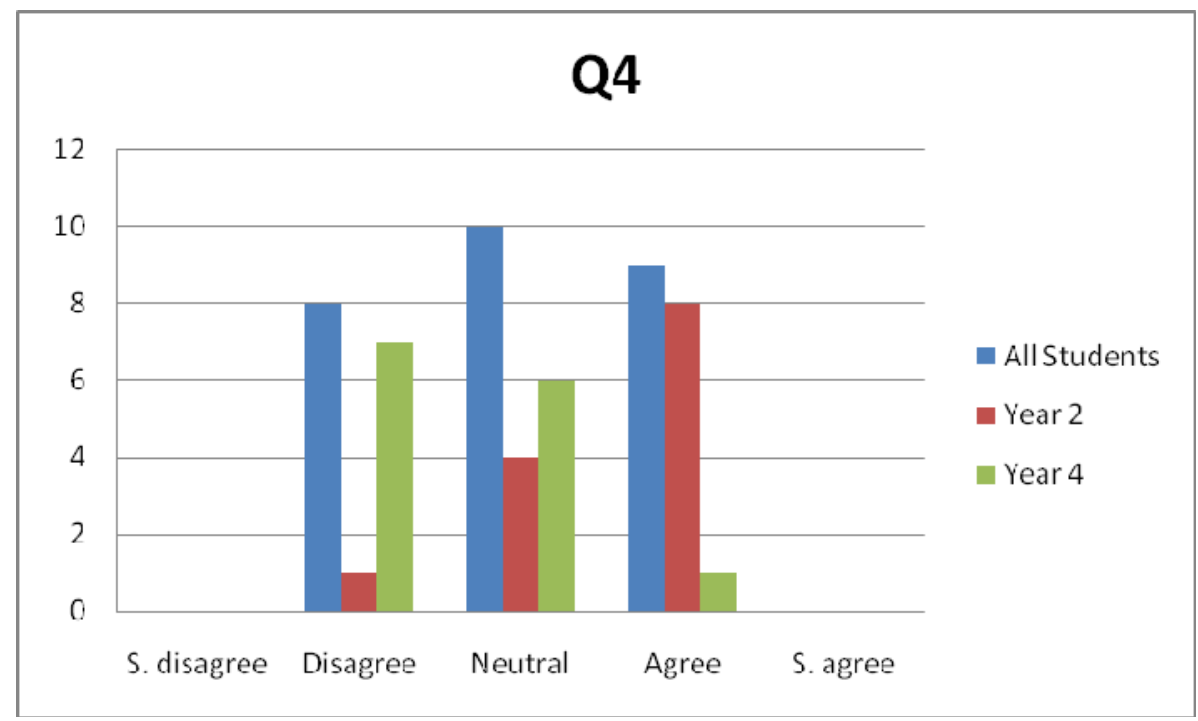

Figure 5: Blended learning enables me to learn more effectively than using only face-to-face approach.

\section{Conclusion and Future Research Directions}

This study compared the online and face-to-face activities between two undergraduate classes. Data are analyzed from tracked statistics provided by the learning platform and their opinions on a questionnaire to provide answers to the research objective which was to examine if blended learning could add value to their learning. It was found the numbers of views for online postings were enormous but the number of messages posted very few. Students gave the highest ratings to the question which were related to having face-to-face activities with students of the other class but the lowest ratings to the question related to feeling more comfortable to communicate with their teachers and classmates online than face-to-face. The findings suggested that participants still preferred the traditional teaching and learning approaches which is very different from the findings in much of the literature (Boyle, 2005; Fang, 2007; Zuckerman-Parker, et al., 2010). 
We acknowledge that the two activities that our student teachers participated in were only an initial opportunity for them to experience blended learning and there are a number of limitations. Firstly, this study presents a small-scale research in this area and it is not appropriate to generalize the findings. Secondly, the participants were undergraduate students who took their courses using traditional face-to-face approach and it was not surprising that they preferred the status quo. Thirdly, although the two classes had classes at different times, they were still located in the same campus and face to face interaction was easy. They could not reap the full benefits of online activities with participants whom they could not easily meet. Fourthly, the high number of views did not guarantee an in-depth reading by the participants. We could get better understanding of students' engagement in different online activities by conducting focus group meetings.

The future direction of this research includes: (1) expand the horizons of online learning by incorporating different formats, particularly digital formats, of learning materials, to replace regular face-to-face lectures to examine whether online delivery is a superior or more enhanced medium for fostering learning; (2) to expand blended learning activities into different modules of the teacher education program to examine if different groups of students would have different preferences; and (3) to conduct content analysis on the postings to determine the presence of certain words or concepts within texts or sets of texts to measure if students have shown improved learning.

\section{References}

Alonso, F., López, G., Manrique, D., \& Vines, J. M. (2005). An instructional model for web-based e-learning education with a blended learning process approach. British Journal of Educational Technology, 36(2), 217-235.

Boyle, T. (2005). A dynamic, systematic method for developing blended learning. Education, Communication and Information, Special Issue on Blended Learning, 5(3), 221-232.

Bruner, J. S. (1986). Acts of meaning. Cambridge, MA: Harvard University Press.

Condie, R., \& Livingston, K. (2007). Blending online learning with traditional approaches: Changing practices. British Journal of Educational Technology, 38(2), 337-348.

Dziuban, C. D., Hartman, J., \& Moskal, P. (2004). Blended learning. Educause Center for Applied Research Bulletin, 7, 1-12.

Eleuterio, M. A., \& Bortolozzi, F. (2004). AMANDA: An intelligent systems for meditating threaded discussions. International Journal on Elearning, 3(3), 13-21.

Fang, L. (2007). Perceiving the useful, enjoyable and effective: A case study of the e-learning experience of tertiary students in singapore. Educational Media International, 337-253(3), 237-253.

Garrison, D. R., \& Kanuka, H. (2004). Blended learning: Uncovering its transformative potential in higher education. The Internet and Higher Education, 7(2), 95-105.

Ginns, P., \& Ellis, R. (2007). Quality in blended learning: Exploring the relationships between on-line and face-to-face teaching and learning. Internet and Higher Education, 10, 53-64.

Guy, T., \& Wishart, C. (2010). Using action research to assess student performance in traditional versus e-learning formats. In E. M. W. Ng (Ed.), Comparative blended learning practices and environments (pp. 112-124). Hershey, PA: Information Science Reference.

Harden, R. M., \& Hart, I. R. (2002). An international virtual medical school (ivimeds): The future for medical education? Medical Teacher, 24(3), 261-267.

Ocker, R., \& Yaverbaum, G. J. (2002). Collaborative learning environments: Exploring student attitudes and satisfaction in face-to-face and asynchronous computer conferencing settings. Journal of Interactive Learning Research, 12(4), 427-448. 
Osguthorpe, R., \& Graham, C. (2003). Blended learning environments definitions and directions. The Quarterly Review of Distance Education, 43(3), 227-233.

Tan, S. C., Turgeon, A. J., \& Johansson, D. H. (2001). Develop critical thinking in group problem solving through computer-supported collaborative argumentation: a case study. Journal of Natural Resources and Life Sciences Education, 30, 97-103.

Zuckerman-Parker, M., Compliment, C., Rodella, M., Ehrlich, G., Post, J. C., Todd, A., et al. (2010). Allegheny Women's Biotechnology Workforce Collaborative: Investing in disadvantaged populations with technology. In E. M. W. Ng (Ed.), Comparative blended learning practices and environments (pp. 204-230). Hershey, PA: Information Science Reference.

\section{Acknowledgments}

The author is very thankful to all learners for participating and giving feedback to this study. Special thanks to Wilson Chung and Rita Wan for research support.

\section{Biography}

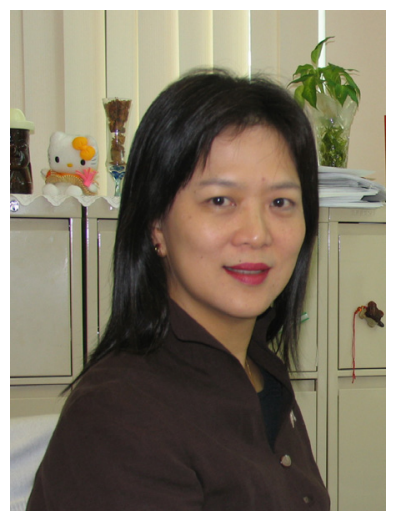

Eugenia M. W. Ng is an Associate Professor in the Mathematics and Information Technology Department and Associate Dean of Graduate School of the Hong Kong Institute of Education. She has been a research investigator of various internal and external funded projects. She has had over seventy articles published in conference proceedings, journals, newspapers and as book chapters. Her publications have appeared in Issues in Informing Science and Information Technology, Journal of Interactive Instruction Development, of Information Systems Education, Journal of Quality School Education and Annals of Cases on Information Technology. Her book chapters have appeared in Subject Teaching and Teacher Education in the New Century: Research and Innovation, and Improving student learning: Learning-oriented assessment in action, Encyclopaedia of Information Technology Curriculum Integration, Encyclopaedia of Information Communications and Technology and Encyclopaedia of Networked and Virtual Organizations. She is the editor of Comparative blended learning practices and environments, Co-editor-in-Chief of International Journal of Web-based Learning and Teaching Technologies, a member of the editorial board of Annals of Cases on Information Technology, and reviewers for Journal of Computers in Human Behavior. 